LETTERS / LETTRES

\section{Stability of Buffered Lidocaine in Glass Vials}

At the author's institution, the use of buffered lidocaine before painful treatment procedures has increased dramatically over the past 4 years, and more than 4500 vials are now used each year. Most vials are used by the peripherally inserted central catheter (PICC) team for insertion of central lines, and the rest are used to aid in insertion of peripheral lines. The benefits of buffered lidocaine as a skin infiltrate during painful procedures relate to the rapid onset of action after injection and the longer duration of sensory blockade. ${ }^{1}$

The addition of sodium bicarbonate to commercial $1 \%$ lidocaine hydrochloride (at a 1:10 ratio) results in a solution containing about $50 \%$ of the local anesthetic as the free base. Solutions prepared this way have a final $\mathrm{pH}$ of about 8.0 (pKa 7.9). This change to the free base increases the rate of penetration of lidocaine into the nerve cell, which in turn significantly decreases the burning sensation at the time of infiltration and speeds up the onset of anesthesia. ${ }^{2-6}$

Although buffered lidocaine has been used in the clinical setting for several years, its long-term physical and chemical stability remains unclear. Two studies examined the chemical stability of buffered lidocaine with and without epinephrine. ${ }^{4,7}$ As a result of the work by Stewart and others, ${ }^{7}$ the author's hospital assigned an arbitrary expiry period of 7 days to solutions of buffered lidocaine $1 \%$; however, this was extrapolated from data generated for $2 \%$ lidocaine solutions. More recently, Pascuet and others $^{8}$ clarified the stability of $1 \%$ and $2 \%$ buffered lidocaine with and without epinephrine packaged in plastic syringes. The period of stability, with refrigerated storage, was 7 days for solutions containing epinephrine and 28 days for epinephrinefree solutions.

The purpose of the study reported here was to determine the physical compatibility and chemical stability of $1 \%$ buffered lidocaine solution packaged in glass vials and stored at room temperature with exposure to light or at $5^{\circ} \mathrm{C}$ with protection from light.

A stock solution of $1 \%$ buffered lidocaine was prepared by adding $10 \mathrm{~mL}$ of sodium bicarbonate $8.4 \%$ (Hospira Healthcare Corporation, Saint-Laurent, Quebec; lot 54-202-EV, expiry June 2009 ) to $100 \mathrm{~mL}$ of $1 \%$ lidocaine solution (Astra-Zeneca Canada Inc, Mississauga, Ontario; lot 9924619-1, expiry April 2010). The solution was filtered through a $0.2-\mu \mathrm{m}$ filter, and 3-mL aliquots were transferred into thirty-six 5-mL glass vials (APP Pharmaceuticals, Schaumburg, Illinois; lot 404079, expiry June 2011). On day zero, 6 vials were collected and frozen at $-70^{\circ} \mathrm{C}$ for later analysis. The rest of the vials were divided into 2 groups: half were stored at $5^{\circ} \mathrm{C}$ with protection from light and the other half were stored at $23^{\circ} \mathrm{C}$ with exposure to light. On days $7,14,28,56$, and 91, 3 vials were removed from each storage condition and frozen at $-70^{\circ} \mathrm{C}$ for later analysis.
Table 1. Stability of Buffered Lidocaine $1 \%$ Solution in Glass Vials

\begin{tabular}{lcc} 
& \multicolumn{2}{c}{$\begin{array}{c}\text { Storage Temperature; \% of } \\
\text { Initial Concentration Remaining* }\end{array}$} \\
\cline { 2 - 3 } Study Day & $\mathbf{2 3 ^ { \circ } \mathbf { C }}$ & $\mathbf{5}^{\circ} \mathbf{C}$ \\
\hline Initial concentration, $\mathrm{mg} / \mathrm{mL}+$ & $8.5 \pm 0.08$ & $10.9 \pm 0.12$ \\
Day 7 & $99.8 \pm 0.9$ & $98.1 \pm 1.4$ \\
Day 14 & $99.4 \pm 1.3$ & $99.3 \pm 0.9$ \\
Day 28 & $95.9 \pm 0.8$ & $97.3 \pm 0.6$ \\
Day 56 & $96.4 \pm 1.0$ & $97.2 \pm 1.0$ \\
Day 91 & $96.7 \pm 0.6$ & $99.6 \pm 1.8$ \\
\hline
\end{tabular}

*Percent of initial concentration remaining is reported as mean \pm standard deviation, based on 3 samples, assayed in duplicate $(n=6)$. tInitial concentration is reported as mean \pm standard deviation, based on 3 samples, assayed in duplicate $(n=6)$.

On the day of analysis, all vials were allowed to thaw for $2 \mathrm{~h}$. The samples were further diluted, and an internal standard was added. Each sample was then analyzed in duplicate by a previously validated stability-indicating high-performance liquid chromatography (HPLC) method. ${ }^{8}$ The $\mathrm{pH}$ of each solution was measured with a calibrated $\mathrm{pH}$ meter, and colour and clarity were determined by the unaided eye against white and black backgrounds.

The concentration of all samples remained above $90 \%$ for a total of 91 days under both storage conditions (Table 1). The $\mathrm{pH}$ rose slightly over the study period (from a mean of 7.89 to a mean of 8.01). All solutions remained clear and colourless for the duration of the study.

On the basis of the information presented here, solutions of $1 \%$ buffered lidocaine packaged in glass vials may be stored at $23^{\circ} \mathrm{C}$ with exposure to light or at $5^{\circ} \mathrm{C}$ with protection from light for up to 91 days.

\section{References}

1. Kennedy RM, Luhmann JD. Pharmacological management of pain and anxiety during emergency procedures in children. Paediatr Drugs 2001;3(5):337-354.

2. Bartfield JM, Homer PJ, Ford DT, Sternklar P. Buffered lidocaine as a local anesthetic: an investigation of shelf life. Ann Emerg Med 1992;21(1):16-19.

3. Christoph RA, Buchanan L, Begalla K, Schwartz S. Pain reduction in local anesthetic administration through $\mathrm{pH}$ buffering. Ann Emerg Med 1988;17(2):117-120.

4. Larson PO, Ragi G, Swandby M, Darcey B, Polzin G, Carey P. Stability of buffered lidocaine and epinephrine used for local anesthesia.J Dermatol Surg Oncol 1991;17(5):411-414.

5. McKay W, Morris R, Mushlin P. Sodium bicarbonate attenuates pain on skin infiltration with lidocaine, with or without epinephrine. Anesth Analg 1987;66(6):572-574.

6. Orlinsky M, Hudson C, Chan L, Deslauriers R. Pain comparison of unbuffered versus buffered lidocaine in local wound infiltration.J Emerg Med 1992;10(4):411-415. 
7. Stewart JH, Cole GW, Klein JA. Neutralized lidocaine with epinephrine for local anesthesia. J Dermatol Surg Oncol 1989;15(10):1081-1083.

8. Pascuet E, Donnelly RF, Garceau D, Vaillancourt R. Buffered lidocaine hydrochloride solution with and without epinephrine: stability in polypropylene syringes. Can J Hosp Pharm 2009;62(5):375-380.

Ronald F Donnelly, MSc(Chem), BSc(Pharm)

Product Development Pharmacist

Department of Pharmaceutical Sciences

The Ottawa Hospital (Civic Campus)

Ottawa, Ontario

\section{Recent Data from the Canadian Hospital Pharmacy Residency Matching Service}

The national Residency Matching Service was introduced by the Canadian Hospital Pharmacy Residency Board (CHPRB) in 2003 in an effort to provide a single process for assigning residents to residency positions that is efficient, effective, and equitable for all involved. All CHPRB-accredited and accreditation-pending residency programs in pharmacy practice must participate in the CHPRB Residency Matching Service. In addition, 4 nonaccredited programs utilize the Residency Matching Service.

The CHPRB is responsible for establishing the policies of the matching service and for monitoring its implementation and use. This letter serves as an update to data presented in $2007 .{ }^{1}$

Overall, since 2003, more than 1400 candidates have sought residency positions through the Residency Matching Service. The data indicate increasing numbers of residency positions in Canada and of candidates applying for residencies. However, growth in the number of residency programs and positions has not met the demand for residency positions. In $2003,70 \%$ of applicants (59 of 84) were matched, but this proportion declined to 29\% (86 of 296) in 2011 (Table 1).

A provincial breakdown of 2011 data from the Residency Matching Service suggests that the number of applicants in each province is 2 to 3 times greater than the number of residency positions available (Table 2).

By 2015, the profession of hospital pharmacy aims that all new pharmacists entering practice in hospitals and related health care settings will have completed a residency accredited by the CHPRB. ${ }^{2}$ Also, with the addition of a new school of pharmacy in Ontario and an increase in class sizes for existing schools of pharmacy, the demand for residency positions is anticipated to increase in the future. Hospitals and related health care settings are encouraged to start residency programs for pharmacists and to expand existing residency programs to keep up with the larger number of pharmacists graduating each year and to meet our professional goals.

\section{References}

1. Kanji Z. Five years of experience with the residency matching service [letter]. Can J Hosp Pharm 2007;60(2):129.

2. CSHP 2015-a practice excellence initiative for pharmacists in hospitals and related healthcare settings. Ottawa $(\mathrm{ON})$ : Canadian Society of Hospital Pharmacists; 2007 [cited 2011 Mar 7]. Available from: www.cshp.ca/programs/cshp2015/index_e.asp

Zahra Kanji, BSC(Pharm), ACPR, PharmD

Residency Matching Service Portfolio

Member, Canadian Hospital Pharmacy Residency Board

Dr Kanji is also a Clinical Pharmacy Specialist-Critical Care, Pharmacy Department, Lions Gate Hospital, and a Clinical Associate Professor, Faculty of Pharmaceutical Sciences, The University of British Columbia, Vancouver, British Columbia.

Table 1. Residency Matching Service of the Canadian Hospital Pharmacy Residency Board: First 9 Years

\begin{tabular}{lcccrrrrrr} 
Variable & $\mathbf{2 0 0 3}$ & $\mathbf{2 0 0 4}$ & $\mathbf{2 0 0 5}$ & $\mathbf{2 0 0 6}$ & $\mathbf{2 0 0 7}$ & $\mathbf{2 0 0 8}$ & $\mathbf{2 0 0 9}$ & $\mathbf{2 0 1 0}$ & $\mathbf{2 0 1 1}$ \\
\hline Programs registered & 28 & 29 & 30 & 31 & 29 & 30 & 30 & 31 & 30 \\
Positions available & 61 & 60 & 64 & 71 & 72 & 76 & 80 & 82 & 86 \\
Registered candidates & 84 & 80 & 92 & 128 & 151 & 179 & 183 & 213 & 296 \\
Matched candidates & 59 & 51 & 62 & 69 & 72 & 76 & 80 & 82 & 86 \\
\hline
\end{tabular}

Table 2. Provincial Breakdown of Matched Candidates

\begin{tabular}{|c|c|c|c|c|c|c|c|c|c|c|}
\hline Province & 2003 & 2004 & 2005 & 2006 & 2007 & 2008 & 2009 & 2010 & 2011 & $\begin{array}{c}\text { Unmatched } \\
\text { Candidates } \\
2011\end{array}$ \\
\hline Alberta & 6 & 2 & 6 & 9 & 10 & 10 & 10 & 9 & 9 & 18 \\
\hline British Columbia & 17 & 14 & 19 & 21 & 19 & 24 & 25 & 24 & 26 & 32 \\
\hline Manitoba & 3 & 2 & 1 & 2 & 2 & 2 & 2 & 2 & 3 & 6 \\
\hline New Brunswick & 2 & 1 & 2 & 2 & 2 & 2 & 2 & 4 & 4 & 1 \\
\hline Nova Scotia & 1 & 2 & 2 & 2 & 2 & 2 & 2 & 2 & 2 & 7 \\
\hline Ontario & 21 & 27 & 28 & 30 & 31 & 31 & 33 & 36 & 36 & 104 \\
\hline Saskatchewan & 3 & 3 & 4 & 3 & 5 & 5 & 6 & 5 & 6 & 21 \\
\hline Total & $53 *$ & 51 & 62 & 69 & $71 \dagger$ & 76 & 80 & 82 & 86 & 189‡ \\
\hline
\end{tabular}

* Six candidates who were matched declined their match

tOne candidate who was matched decline the match.

FIn addition to the unmatched candidates listed here, there were 13 unmatched foreign candidates, 5 unmatched candidates from the United States, 2 unmatched candidates from Quebec, and 1 unmatched candidate from Newfoundland and Labrador, for an overall total of 210 unmatched candidates. 